\title{
Cobalt Amide Imidate Imidazolate Frameworks as Highly Active Oxygen Evolution Model Materials
}

\author{
Alberto Bucci, ${ }^{\dagger}$ Suvendu Sekhar Mondal, ${ }^{\dagger}$ Vlad Martin-Diaconescu, ${ }^{\dagger}$ (i) Alexandr Shafir, ${ }^{\S}$ \\ and Julio Lloret-Fillol $*, \dagger, \ddagger$ \\ ${ }^{\dagger}$ Institute of Chemical Research of Catalonia (ICIQ), The Barcelona Institute of Science and Technology, Avinguda Països Catalans, \\ 16, 43007 Tarragona, Spain \\ ¥Catalan Institution for Research and Advanced Studies (ICREA), Lluïs Companys, 23, 08010 Barcelona, Spain \\ ${ }^{\S}$ Institute of Advanced Chemistry of Catalonia IQAC-CSIC, c/Jordi Girona 18-26, 08034 Barcelona, Spain \\ Supporting Information
}

ABSTRACT: Two imidazolate-based Co-MOFs, IFP-5 and IFP8 (imidazolate framework Potsdam), with a different peripheral group $-\mathrm{R}$ ( $-\mathrm{Me}$ and $-\mathrm{OMe}$, respectively) have been synthesized by a solvothermal method and tested toward the oxygen evolution reaction (OER). Remarkably, IFP-8 presents much lower overpotentials $\left(319 \mathrm{mV}\right.$ at $10 \mathrm{~mA} / \mathrm{cm}^{2}$ and $490 \mathrm{mV}$ at 500 $\mathrm{mA} / \mathrm{cm}^{2}$ ) than IFP-5 toward OER, as confirmed by online gas chromatography measurements (Faradaic yield of $\mathrm{O}_{2}>99 \%$ ). Moreover, the system is extraordinarily stable during $120 \mathrm{~h}$, even when used as a catalyst toward the overall water splitting reaction without any sign of fatigue. An integrated ex situ spectroscopic study, based on powder X-ray diffraction, extended X-ray absorption fine structure, and attenuated total reflection, allows

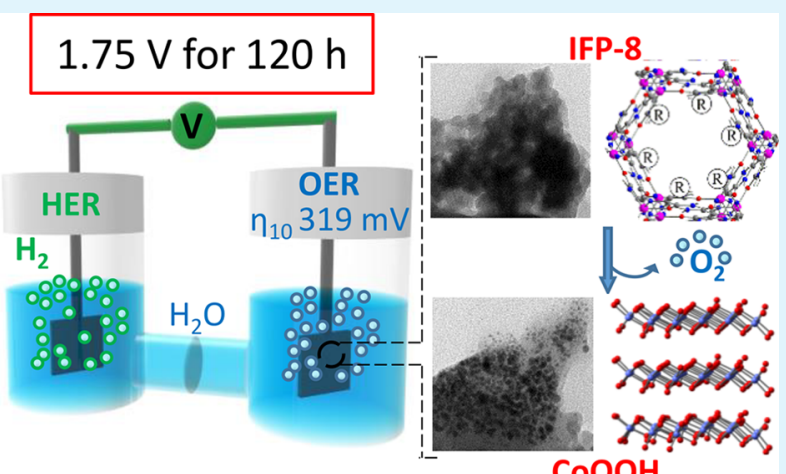
the identification of the active species and the factors that determine the catalytic activity. Indeed, it was found that the performances are highly affected by the nature of the $-\mathrm{R}$ group, because this small change strongly influences the conversion of the initial metal organic framework to the active species. As a consequence, the remarkable activity of IFP- 8 can be ascribed to the formation of $\mathrm{Co}(\mathrm{O}) \mathrm{OH}$ phase with a particle size of a few nanometers $(3-10 \mathrm{~nm})$ during the electrocatalytic oxygen evolution.

KEYWORDS: metal-organic framework (MOF), imidazolate framework Potsdam (IFP), oxygen evolution reaction, electrocatalysis, cobalt

\section{INTRODUCTION}

The oxygen evolution reaction (OER) is the ideal process for accessing a diverse number of renewable fuels and chemicals, ${ }^{1,2}$ but its applicability is hampered by the difficulty to obtain stable and efficient catalysts. ${ }^{3,4}$ Cobalt-based OER catalysts, both molecular ${ }^{5}$ and heterogeneous, ${ }^{6-10}$ have attracted enormous interest because of their relatively high activities and the metal's abundance in the earth crust. Homogeneous molecular catalysts can be finely tuned to improve performances and allow for mechanistic studies, but the poor stability and recyclability of the reported systems hinder their applications. ${ }^{11}$ In contrast, heterogeneous catalysts are more stable and cost-effective, ${ }^{12}$ although the formation of the active centers on solid catalytic surfaces is difficult to control, identify, and quantity, making mechanistic studies very challenging. ${ }^{13}$ Besides the well-investigated applications such as adsorption, ${ }^{14}$ storage, ${ }^{15}$ separation, ${ }^{16}$ and conventional catalysis, ${ }^{17-20}$ metalorganic frameworks (MOFs) are emerging materials for OER. $^{21}$ Among Co-based MOFs, ZIF-67 (ZIF = zeolitic imidazolate framework) is one of the benchmarks for oxygen evolution under several different working conditions. Indeed, it was demonstrated to be able to perform 21 TONs with a TOF of $0.035 \mathrm{~s}^{-1}$ under photocatalytic conditions, whereas if supported onto FTO (fluorine-doped tin oxide), ZIF-67 operates under a wide range of $\mathrm{pH}$, requiring $1.73 \mathrm{~V}$ vs NHE to give a stable current of $1 \mathrm{~mA} / \mathrm{cm}^{2}$ (at $\left.\mathrm{pH} 9\right) .^{22}$ Nevertheless, the performances are quite far from those required for applications, because the poor conductivity of the framework generally hampers the direct use of MOFs in electrocatalysis. $^{23-31}$ Alternatively, MOFs can be subjected to framework degradation either by thermal decomposition, ${ }^{32-35}$ chemical oxidation, ${ }^{36}$ or in situ electrochemical aging, ${ }^{37,38}$ in order to afford carbon/metal or metal oxide composites with improved performances. ${ }^{39-42}$ As an example, An et al. demonstrated that thermal decomposition of ZIF-67 affords ultrathin $\mathrm{Co}_{3} \mathrm{O}_{4}$ nanomesh, rich in oxygen defects, with

Received: October 7, 2019

Accepted: November 19, 2019

Published: November 19, 2019 
remarkable performances at $\mathrm{pH} 14\left(\eta=370 \mathrm{mV}\right.$ at $10 \mathrm{~mA} / \mathrm{cm}^{2}$ and a Tafel slope of $74 \mathrm{mV} / \mathrm{dec}),{ }^{43}$ whereas Wang and coworkers improved the performances of $\mathrm{Zn}_{0.2} \mathrm{Co}_{0.8} \mathrm{OOH}$ via chemical oxidation of ZIF-67 in the presence of $\left(\mathrm{NH}_{4}\right)_{2} \mathrm{~S}_{2} \mathrm{O}_{8}$, lowering $\eta_{10}$ to only $235 \mathrm{mV}$. $^{36}$

A clear advantage of those approaches consists in the possibility to control the formation of the new phases by changing the reaction condition. However, when the MOF undergoes electrochemical aging, the system becomes much more dynamic, and the identification of the active species is uncertain and sometimes controversial. ${ }^{37,38,44}$ For example, Ai and co-workers proposed the conversion of UTSA-16 to $\mathrm{CoO}_{x}$ active phase under OER conditions, ${ }^{38}$ whereas Zhang et al. suggested that electrochemical aging in $\mathrm{O}_{2}$ saturated electrolyte induces the exfoliation of a $3 \mathrm{D}$ pillared-layer structure to achieve a 2D amorphous ultrathin phase, excluding the possibility to form $\mathrm{CoO}_{x}$ because of its much lower activity. ${ }^{37}$ Moreover, Fischer et al. proposed that the active phase of ZIF9 consists of a nitrogen-coordinated cobalt oxyhydroxide $\mathrm{N}_{4} \mathrm{COOH}$ species. $^{44}$

In order to understand how to control the transformation of the MOF to the active catalytic phase, we used two model systems named IFP (imidazolate framework Potsdam), ${ }^{45,46}$ based on penta-coordinated Co secondary building units (SBU's) connected by multidentate amido-imidate-imidazolate linkers. The models differ in the nature of the substituent at the imidazole C2 position, which can be either a -Me (IFP-5) or an $-\mathrm{OMe}$ (IFP-8) group. We have studied the OER activity of IFP-5 and IFP-8 under basic conditions ( $\mathrm{pH} 14$ and 13), demonstrating their high catalytic activity. More interestingly, the ex situ X-ray absorption spectra (XAS), powder X-ray diffraction (PXRD), and attenuated total reflection (ATR) experiments gave insight into how the transformation of the framework is able to tune the formation of the active species, which leads to excellent catalytic performances.

\section{RESULT AND DISCUSSION}

Synthesis and Characterization. The synthesis of Coamide-imidate-imidazolate frameworks $\left[\mathrm{Co}\left(\mathrm{C}_{5} \mathrm{H}_{3} \mathrm{~N}_{4} \mathrm{O}_{2}\right)-\mathrm{R}\right.$ ] (with $\mathrm{R}=-\mathrm{Me}^{45}$ and $-\mathrm{OMe}^{46}$ ) were previously reported by Holdt et al. The synthesis of the MOFs proceeds by the reaction of 2-substituted-4,5-dicyanoimidazole under solvothermal conditions in the presence of $\mathrm{Co}\left(\mathrm{NO}_{3}\right)_{2} \cdot 6 \mathrm{H}_{2} \mathrm{O}$ (see the Supporting Information (SI) for details). During the reaction, the partial hydrolysis of the ligand affords the imidazolate-4-amide-5-imidate $\left(\mathrm{C}_{5} \mathrm{H}_{3} \mathrm{~N}_{4} \mathrm{O}_{2}\right)$, which is the real linker of the IFP (Figure 1, top).

For comparison, the canonical ZIF-67 was synthesized according to the reported literature procedure. ${ }^{47}$ The experimental PXRD patterns, with the simulated ones, as well as XAS of the as synthesized IFPs are shown in Figure 2.

The experimental diffraction patterns perfectly match the simulated ones, showing characteristic peaks at $7.4^{\circ}, 9.9^{\circ}$, $15.9^{\circ}, 17.3^{\circ}, 23.3^{\circ}$, and $30.2^{\circ}$. The sharpness of the diffraction peaks indicates that the newly obtained IFP-5 is highly crystalline, whereas IFP-8 is less so.

Furthermore, the ATR spectrum (Figure S1) clearly shows the presence of characteristic bands around 1560 and 1660 $\mathrm{cm}^{-1}$, which are due to the formation of amide and imide groups. Furthermore, between 3320 and $3330 \mathrm{~cm}^{-1}$, a broad amide-imidate $\mathrm{N}-\mathrm{H}$ band with a considerably fine structure was observed.

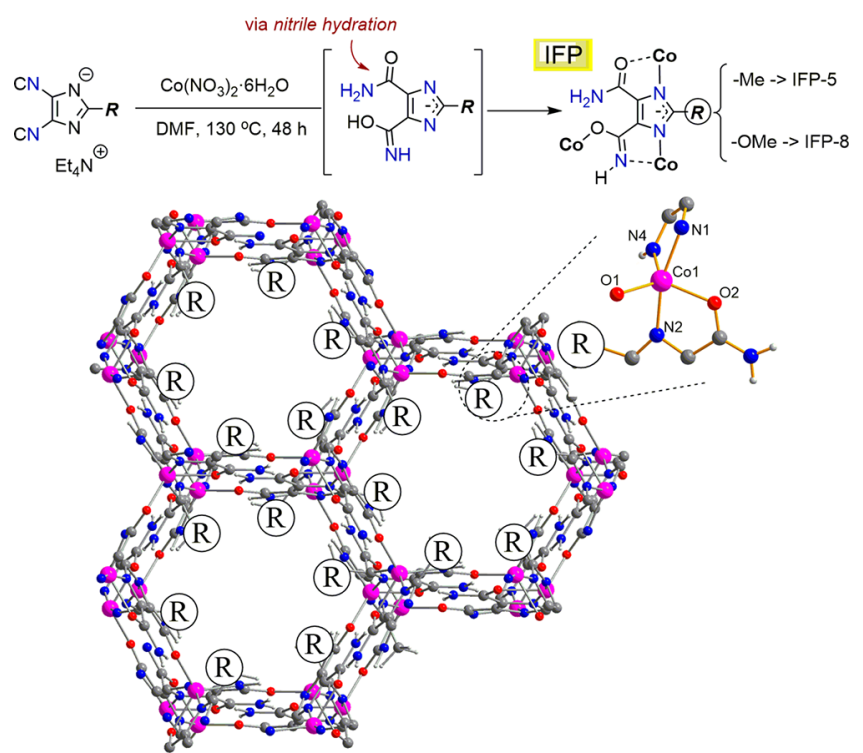

Figure 1. Top: general synthetic strategy of IFP frameworks, highlighting the in situ ligand hydrolysis. Bottom: 1D hexagonal channel structure of IFP, with an enlargement of the asymmetric unit of IFPs, clarifying the $\mathrm{Co}^{2+}$ coordination environment. The label $\mathrm{R}$ stands for $-\mathrm{Me}$ and $-\mathrm{OMe}$ in the case of IFP-5 and IFP-8, respectively.

The Co K-edge of the extended X-ray absorption fine structure (EXAFS) spectra of IFPs show pre-edge $1 \mathrm{~s} \rightarrow 3 \mathrm{~d}$ transitions centered around $7709.5 \mathrm{eV}$ and rising edges at $7721.2 \mathrm{eV}$. These features are 0.4 and $1.5 \mathrm{eV}$ lower in energy than the mixed $\mathrm{Co}^{2+} / \mathrm{Co}^{3+}$ centers in the $\mathrm{Co}_{3} \mathrm{O}_{4}$ reference, which is consistent with the $\mathrm{Co}^{2+}$ oxidation state for the IFP series. Moreover, EXAFS analysis (Figure S2) shows a 5coordinated metal center having two first coordination sphere $\mathrm{N} / \mathrm{O}$ scattering shells, with $2 \mathrm{~N} / \mathrm{O}$ atoms at $2.00 \AA$ and $3 \mathrm{~N} / \mathrm{O}$ atoms at $2.11 \AA$. On the other hand, ZIF-67 has an intense preedge at $7709.9 \mathrm{eV}$ that can be rationalized in terms of increased $\mathrm{p}-\mathrm{d}$ mixing due to its tetrahedral geometry. Conversely to what is observed for the IFP model, ZIF-67 is better described by a single shell of N/O scattering atoms at $2.00 \AA$.

Putting together the pieces of information obtained, the chemical environment of the $\mathrm{Co}^{2+}$ ion in the IFP series is constituted by five donor atoms of three ligands to form a distorted trigonal-bipyramidal geometry (Figure 1, down). In this arrangement, the imidate $\mathrm{N} 4$ and $\mathrm{O} 2$ and the amide $\mathrm{O} 1$ reside in equatorial positions, with the two imidazolate $\mathrm{N}$ atoms (N1 and N2) occupying the axial positions. The multidentate imidazolate-based ligands, produced by the in situ hydration of the dicyano precursor, combine with $\mathrm{Co}^{2+}$ ions to form the neutral microporous imidazolate MOF with 1-D hexagonal channels. The $\mathrm{Co}^{2+}$ SBUs at the IFP structure and the bridging ligands act as 3-connected topological species forming a net with a uninodal topology, named etb. The functional groups at the imidazolic C2 position protrude into the channel opening, tuning the pore aperture $(4.2-1.7 \AA)$, polarity, and functionality of the channel walls (Figure 1). As a consequence, the specific surface area of IFP is much higher for IFP-5 $\left(666.2 \mathrm{~m}^{2} \mathrm{~g}^{-1}\right)$ than for IFP-8 $\left(45.8 \mathrm{~m}^{2} \mathrm{~g}^{-1}\right)$ based on the narrowing the pore aperture window of the IFP structure (Figure S3). The scanning electron microscopy (SEM) analysis of IFP samples (Figure S4) revealed that IFP-5 

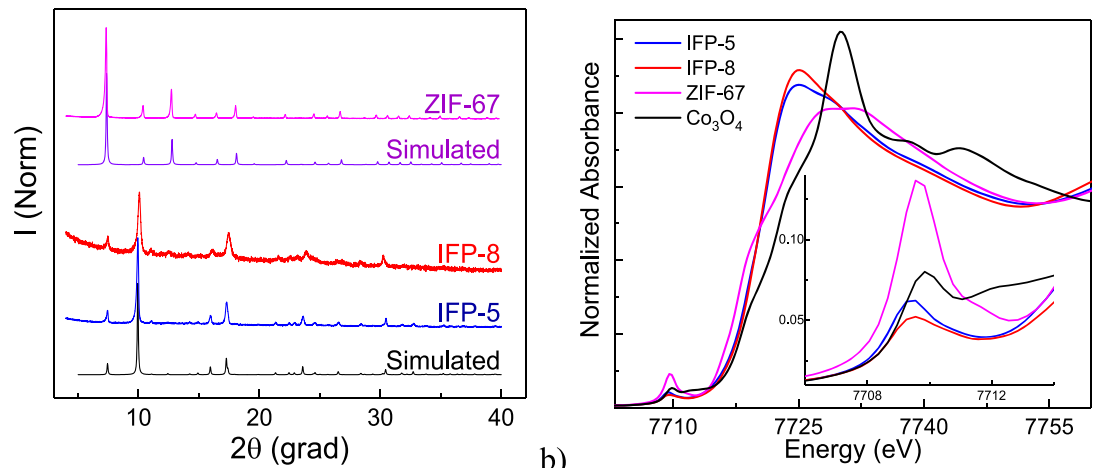

a)

Figure 2. PXRD pattern (a) and Co K-edge X-ray absorption near edge structure (XANES) profiles (b) of IFP-5 (blue), IFP-8 (red), and ZIF-67 (magenta). $\mathrm{Co}_{3} \mathrm{O}_{4}$ (black) was used as a reference in the XANES.
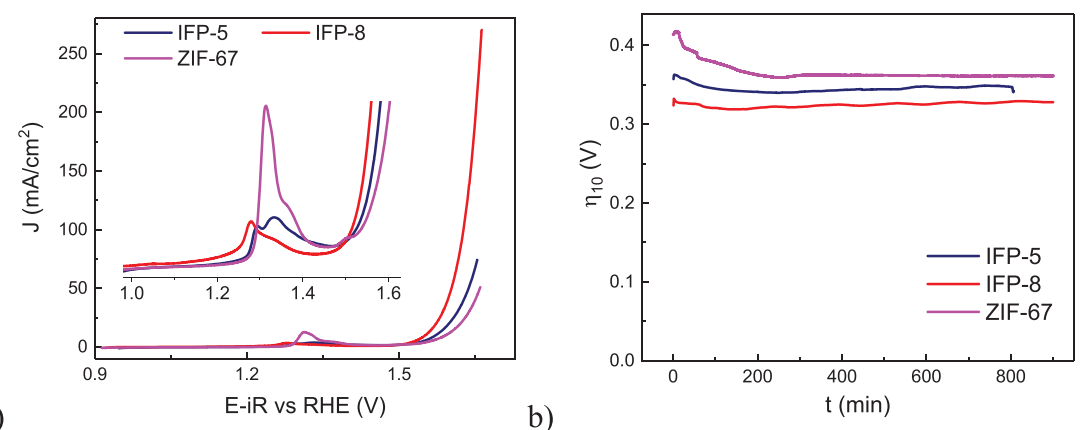

a)

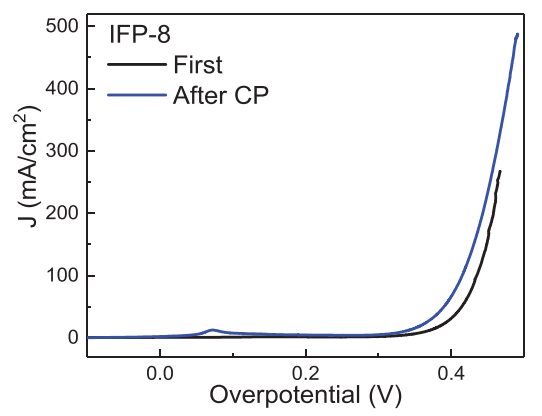

c)

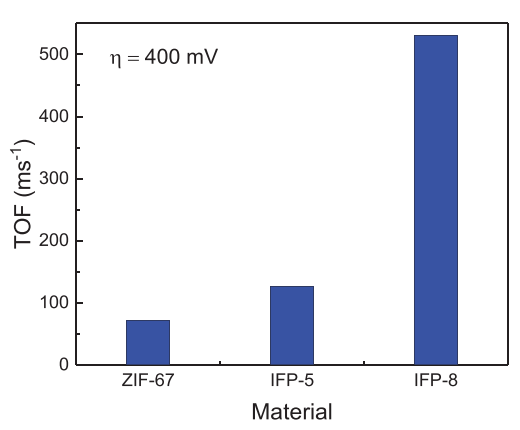

e)

f) d)
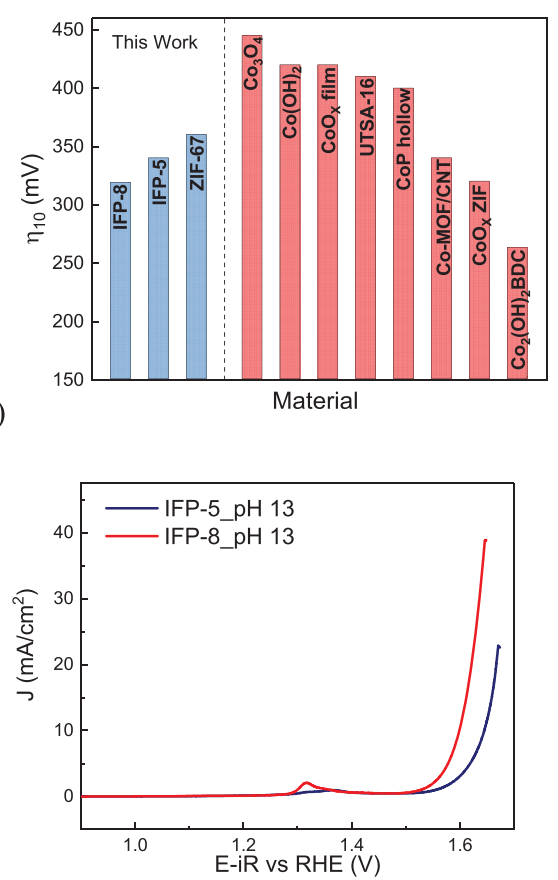

Figure 3. (a) Polarization curves and (b) long-term chronopotentiometry (CP) at $J=10 \mathrm{~mA} / \mathrm{cm}^{2}$ for IFP-5 (blue), IFP-8 (red), and ZIF-67 (magenta); (c) LSV of IFP-8 before (black) and after (blue) the CP; (d) comparison in the overpotential at $10 \mathrm{~mA} / \mathrm{cm}^{2}$ with the most common MOFs in the literature at $\mathrm{pH} 14$; (e) evaluation of the nominal TOF for the material studied calculated at $\eta=400 \mathrm{mV}$ and the catalyst loading taking account for the leaching (vide infra) and (f) performances of IFP materials at $\mathrm{pH} 13(0.1 \mathrm{M} \mathrm{KOH})$. For all the experiments, the current collector used was a $1 \times 1 \mathrm{~cm}^{2}$ geometric area of NF.

displays hexagonal nanostructures, whereas IFP-8 forms spherical morphologies.

In order to investigate the chemical stability of the assynthesized IFP materials, these were subjected to aging under very basic conditions. The final PXRD patterns revealed no obvious pronounced changes after 24 and $72 \mathrm{~h}$ at $\mathrm{pH} 13$ (Figure S5), but some modifications took place when the $\mathrm{pH}$ was raised to 14 . The new samples, labeled IFP-Xbt (where X identifies the corresponding IFP number and bt stands for "basic treatment") were characterized via PXRD and ATR 

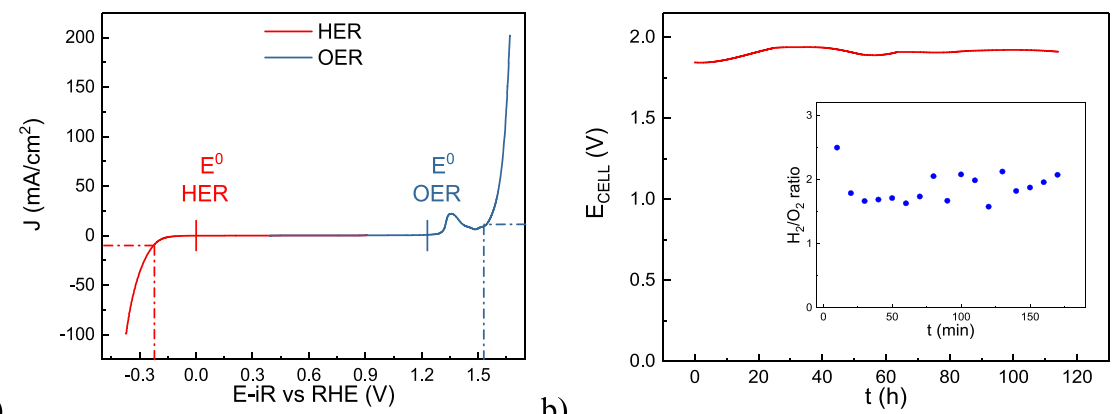

a)

Figure 4. (a) Overall water splitting LSV (in red, HER region and in blue OER region). The potentials at $10 \mathrm{~mA} / \mathrm{cm}^{2}$ are highlighted in the picture, whereas thermodynamic potential for HER and OER are marked as $E^{0}$ in the figure. (b) Represents a CP experiment carried out at $10 \mathrm{~mA} /$ $\mathrm{cm}^{2}$ during $120 \mathrm{~h}$ for the overall water splitting reaction (inset shows the $\mathrm{H}_{2} / \mathrm{O}_{2}$ ratio recorded during the measurement). All the measurements were performed at $\mathrm{pH} 14$ by $\mathrm{KOH}$, supporting IFP-8 onto NF.

spectroscopy (Figures S6, S7). The broadening of the PXRD peaks clearly suggests the partial loss of crystallinity (Figures S6a, S7a). In the ATR spectrum, a very sharp stretching at $3630 \mathrm{~cm}^{-1}$ appears (Figures S6b, S7b) consistent with the formation of hydroxyl groups, indicating the occurrence of hydrolysis. Interestingly, the intensity of the signals at ca. 2800 and $1100 \mathrm{~cm}^{-1}$ that are attributable to $\mathrm{CH}_{3}-\mathrm{O}$ and $\mathrm{C}-\mathrm{O}-\mathrm{C}$ stretching, respectively, ${ }^{48}$ decreases in IFP-8bt, whereas the intensities of all peaks are maintained for IFP-5 after the basic treatment, suggesting different lability of the corresponding $\mathrm{R}$ group toward hydrolysis. ${ }^{46}$

Along with the molecular precursors, we also synthesized the corresponding cobalt oxides $\mathrm{Co}_{3} \mathrm{O}_{4}$-X (when $\mathrm{X}$ is 5 or 8 , stands for IFP-5 and IFP-8, respectively; whereas, when $\mathrm{X}$ is 67 or $\mathrm{R}$, stands for the calcinated ZIF-67 and the reference $\mathrm{Co}_{3} \mathrm{O}_{4}$, respectively). The synthetic procedure to obtain $\mathrm{Co}_{3} \mathrm{O}_{4}$ spinels involves a simple thermal treatment at $700{ }^{\circ} \mathrm{C}$ of the corresponding IFP under $\mathrm{N}_{2}$ atmosphere (Figure S8), followed by acid etching in $0.5 \mathrm{M} \mathrm{H}_{2} \mathrm{SO}_{4}$ for $2 \mathrm{~h}$, that affords $\mathrm{Co}_{3} \mathrm{O}_{4}$ phase as demonstrated by PXRD, ATR, XAS (Figure S9), SEM (Figure S10), and TEM (Figure S11 and S12) analysis, with an average particle size of $46 \mathrm{~nm}$.

Electrocatalytic OER, Ex Situ Characterization of Catalytic Materials. As an initial step, we compared the electrochemical performances at $\mathrm{pH} 14$ of IFPs and ZIF-67 (ZIF-67 has been used as a reference under exactly the same reaction conditions) by drop casting $200 \mu \mathrm{g}$ of the corresponding material onto the nickel foam (NF).

Remarkably, IFPs exhibit better performances than the wellknown ZIF-67 benchmark. IFP-8 is the most active electrocatalyst (Figure $3 \mathrm{a}-\mathrm{d}$ ), with a low overpotential at $10 \mathrm{~mA} / \mathrm{cm}^{2}$ $\left(\eta_{10}\right)$ of 319 and $257 \mathrm{mV}$ at the onset, respectively (Figure S13). Also, the Tafel slope of $64 \mathrm{mV} / \mathrm{dec}$ is particularly low (Figure S14). The $\eta_{10}$ for the other tested catalysts are 340 and $360 \mathrm{mV}$, whereas the onsets are 273 and $269 \mathrm{mV}$ for IFP-5 and ZIF-67, respectively (Figure S13). The values of the Tafel slope (Figure S14) are slightly higher (ca. $70 \mathrm{mV} / \mathrm{dec}$ for both). Such values are considerably lower than previously reported cobalt-based MOF benchmarks, as those reported by and Pang and $\mathrm{Qu}^{30,31}$

In order to rationalize this remarkable activity, electrochemical impedance spectroscopy (EIS) in the potential range of $0.9-1.8 \mathrm{~V}$ vs RHE has been performed. The resistance associated with OER increases from IFP-8 $(1.9 \Omega$ at $1.6 \mathrm{~V}$ vs RHE) to IFP-5 (2.6 $\Omega$ at $1.6 \mathrm{~V}$ vs RHE), whereas the values of the pseudocapacitance for the different catalysts inversely fit this trend, since IFP- 8 has the highest capacitance in the entire potential window investigated (Figure S15 and Table S1). This is an indication that IFP-8 exhibits a higher electrochemical surface area (ECSA) with respect to IFP-5 and, consequently, a higher number of active sites exposed. Indeed, the ECSA measured from the double layer capacitance is 11.2 and 2.7 $\mathrm{cm}^{2}$ for IFP-8 and IFP-5, respectively (see SI for calculation details).

Remarkably, chronopotentiometry (CP) at $10 \mathrm{~mA} / \mathrm{cm}^{2}$ (Figure $3 b$ ) shows a slight decrease in the overpotential for both IPFs at the beginning of the CP, but then it remains stable during the successive $13 \mathrm{~h}$, clearly indicating that an activation process occurs. Indeed, $\eta_{10}$ of IFP- 8 is $319 \mathrm{mV}$ after the activation phase, and the $\eta_{50}$ became as low as $390 \mathrm{mV}$ (Figure 3c). Furthermore, a remarkable and sustained current of $480 \mathrm{~mA} / \mathrm{cm}^{2}$ was observed at an overpotential as low as 490 $\mathrm{mV}$. Such stability is uncommon for simply deposited MOF on the electrode material so this prompts us to push the stability tests toward a very long CP run during $180 \mathrm{~h}$ at $10 \mathrm{~mA} / \mathrm{cm}^{2}$ (Figure S16). For comparison, the bioinspired cobalt-citrate MOF, UTSA-16, needs $408 \mathrm{mV}$ of overpotential to deliver a stable current of $10 \mathrm{~mA} / \mathrm{cm}^{2}$ during $7 \mathrm{~h}$ before deactivation, ${ }^{38}$ whereas the $\mathrm{Co}_{2}(\mathrm{OH})_{2} \mathrm{BDC}$ nanosheets recently reported by Pang et al., exhibit much lower $\eta_{10}(273 \mathrm{mV})$ and $\eta_{50}$ of ca. 360 $\mathrm{mV}$, but such outstanding activity at $\mathrm{pH} 14$ is maintained for only $3 \mathrm{~h}$, before that current drops up to $60 \%$ of its initial value and $\eta_{50}$ increases up to $410 \mathrm{mV}$ (as estimated by LSV showed therein). ${ }^{30}$ In general, the performances of IFPs are much better than the majority of Co-based MOFs and even with respect to many pure inorganic materials (Figure $3 \mathrm{~d}$ and Table S4). ${ }^{25,49}$

Nevertheless, we performed an additional long-term chronopotentiometry experiment $\left(4 \mathrm{~h}\right.$ at $\left.20 \mathrm{~mA} / \mathrm{cm}^{2}\right)$ aimed at monitoring the gas evolution by means of online gaschromatography (see SI for calculation details). A quantitative Faradaic efficiency $(>99 \%)$ was found during the entire experiment for both IFP-5 and IFP-8 (Figure S16), which ensures that the current measured is due to $\mathrm{O}_{2}$ evolution.

According to the measures of the inductively coupled plasma optical emission spectrometry (ICP-OES), IFP-8 also has the highest nominal TOF value $\left(0.53 \mathrm{~s}^{-1}\right.$ at $\left.\eta=0.4 \mathrm{~V}\right)$ over IFP-5 and ZIF-67 (Figure 3e). However, it should be noted that these TOF values are an underestimation of the real performances because they are calculated under the assumption that all the catalytic centers equally participate in catalysis. ${ }^{50}$ However, even the nominal TOF value reported for 


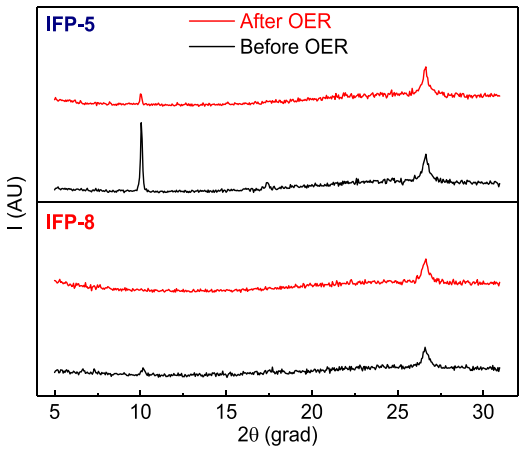

a)

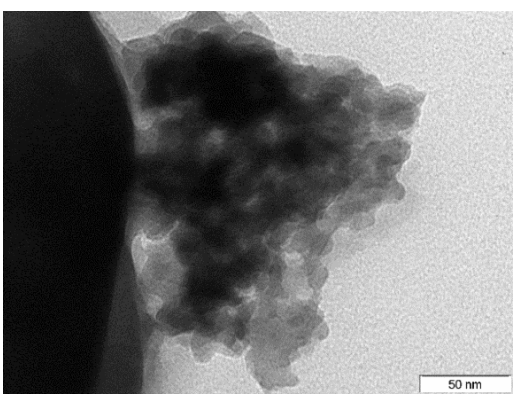

c)

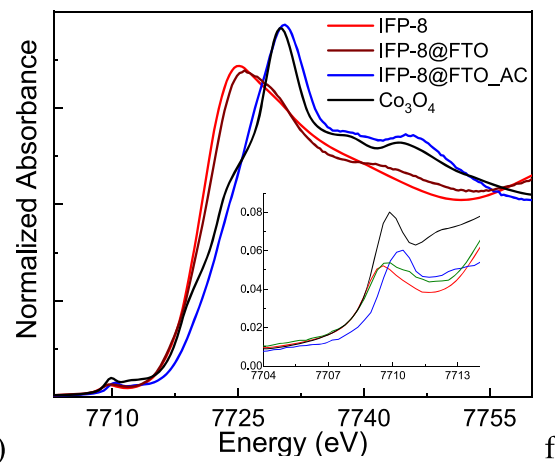

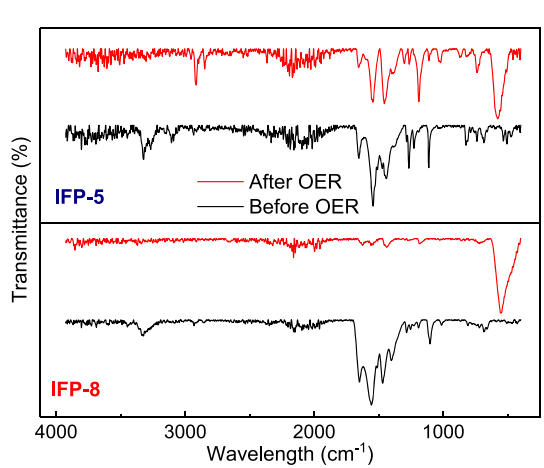

b)
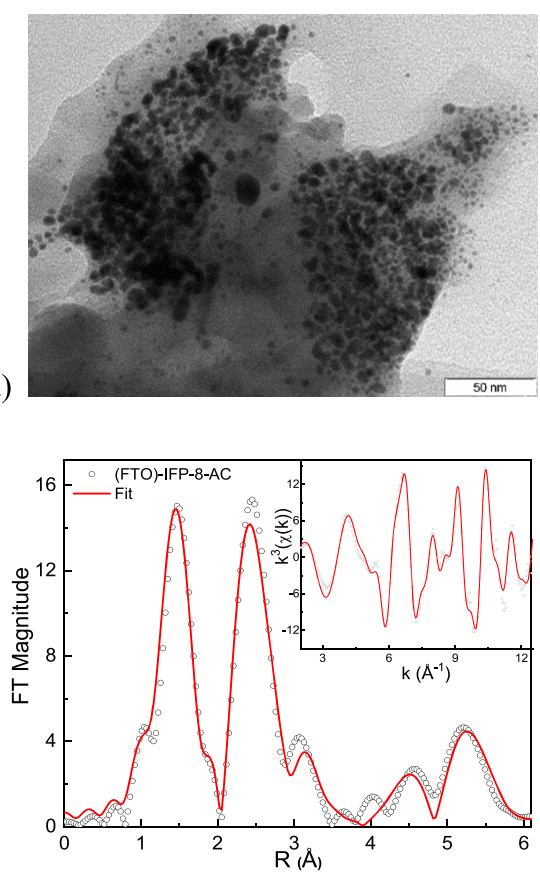

Figure 5. Characterization of IFP materials plated on FTO. Panels (a) and (b) offer a comparison between PXRD pattern and ATR before (black) and after (red) OER for IFP-5 (upper) and IFP-8 (lower), respectively, whereas TEM images (scale bars $=50$ nm) are depicted for IFP-8 before (c) and after (d) OER. (e) Co K-edge XANES profiles for the IFP-8 measured as a pellet (red line) and supported in FTO before (dark red line) and after catalysis (blue line) versus the $\mathrm{Co}_{3} \mathrm{O}_{4}$ reference (black line). Fourier transformed EXAFS data and corresponding fits within the inset showing k-space spectra of IFP-8 supported in FTO after catalysis (f).

IFP-8 largely exceeds the most common benchmarks reported so far; for example, that of Co-MOF nanosheet array directly grown on NF $\left(0.18 \mathrm{~s}^{-1}\right.$ at $\left.\eta=0.4 \mathrm{~V}\right)$ recently reported by $\mathrm{Qu}$ et al. ${ }^{31}$

Since the chemical stability tests revealed that IFPs at $\mathrm{pH} 13$ do not suffer of partial hydrolysis, the same measurements were performed at this lower $\mathrm{pH}$ (Figure 3f). Remarkably, the activity of IFPs is competitive even under these conditions, and indeed, $\eta_{10}$ are 360 and $410 \mathrm{mV}$ for IFP-8 and IFP-5, respectively, which are comparable with similar single Cobased MOF MCF-12 nanosheets recently reported by Zhang et al. $\left(\eta_{10}=310 \mathrm{mV}\right)^{37}$ and largely exceeding the performances of other benchmarks as MAF-X27-OH $\left.\left(\eta_{10}=461 \mathrm{mV}\right)\right)^{25}$ $\operatorname{MOF}\left(\mathrm{Fe}_{1}-\mathrm{Co}_{3}\right)_{550 \mathrm{~N}}\left(\eta_{10}=390 \mathrm{mV}\right),{ }^{51}$ including inorganic materials. ${ }^{52-54}$ Interestingly, at this $\mathrm{pH}$, the $\eta_{10}$ drifts after $12 \mathrm{~h}$ of long-term chronopotentiometry experiments $(15 \mathrm{~h}$ at 10 $\mathrm{mA} / \mathrm{cm}^{2}$ ), approaching 500 and $680 \mathrm{mV}$ (Figure S17).

The remarkably low overpotentials at $10 \mathrm{~mA} / \mathrm{cm}^{2}$ prompt us to study IFP-8 as a bifunctional catalyst for both OER and hydrogen evolution reaction (HER) and therefore as a water splitting catalyst. HER tests (Figure S18) were performed in a three-electrode cell with the same configuration as for OER, but this time, the electrolyte solution was continuously degassed by $\mathrm{N}_{2}$ flow, in order to remove $\mathrm{O}_{2}$. Furthermore, the potential at the working electrode was varied between 0.9 $\mathrm{V}$ to $-0.5 \mathrm{~V}$ vs RHE at a scan rate of $1 \mathrm{mV} / \mathrm{s}$. The $\eta_{10}$ of 227 $\mathrm{mV}$ is quite lower if compared to other Co-based catalysts $^{10,55-58}$ and competitive with the most recent Cobased hybrid systems. ${ }^{59-61}$ As indicated in Figure 4, the overall water splitting reaction can be performed at $10 \mathrm{~mA} / \mathrm{cm}^{2}$ by applying ca. $1.89 \mathrm{~V}$. A long CP experiment highlights the extreme durability of IFP-8 under total water splitting conditions (for $120 \mathrm{~h}$ at $10 \mathrm{~mA} / \mathrm{cm}^{2}$ ), as the activity remains rather constant for the entire duration of the experiment without suffering apparent fatigue (Figure 4b). The overall water splitting is confirmed by the online measured $\mathrm{H}_{2} / \mathrm{O}_{2}$ ratio of ca. 1.9, with quantitative faraday efficiency during the first $3 \mathrm{~h}$ of reaction (Figure S19). In total, after $120 \mathrm{~h}$ of electrolysis, minimum TONs of 26000 and 13000 are 

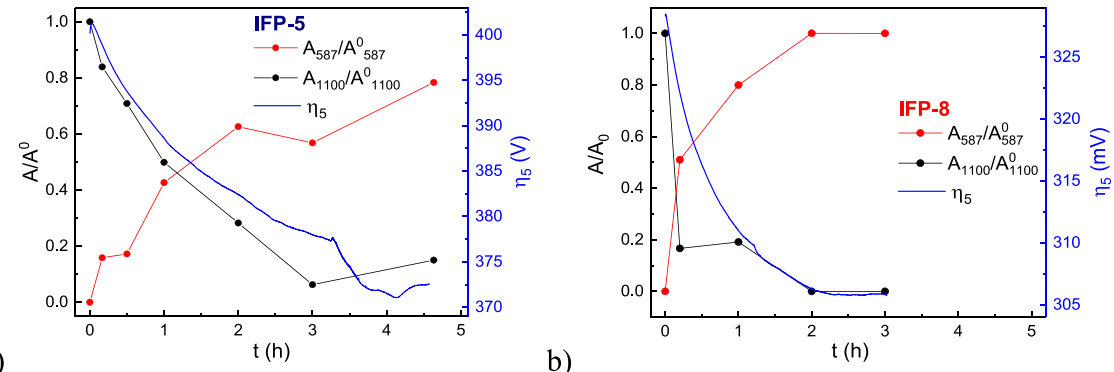

Figure 6. Comparison of the CP activation (blue line) of IFP-5 (a) and IFP-8 (b) with the formation of the catalytic active species (red dots) and the disappearance of the organic framework (black dots). The values of the ATR areas of the organic region are normalized to the initial values calculated at $t=0$. For those experiments, IFPs were supported onto the FTO electrode and employed in $1 \mathrm{M} \mathrm{KOH}$ solution.

calculated for $\mathrm{H}_{2}$ and $\mathrm{O}_{2}$, respectively, considering all the deposited material over the electrode.

In order to disclose the origin of the difference in the activity among those catalysts and the mechanism of activation, we performed several experiments. First of all, IFPs were compared to their related calcinated derivatives $\mathrm{Co}_{3} \mathrm{O}_{4}-\mathrm{X}$ samples and $\mathrm{Co}_{3} \mathrm{O}_{4}-\mathrm{R}$, the latter prepared independently via solution combustion synthesis (see SI for further details). IFP8 exhibits much higher performances than both $\mathrm{Co}_{3} \mathrm{O}_{4}-8\left(\eta_{10}\right.$ $=380 \mathrm{mV})$ or the $\mathrm{Co}_{3} \mathrm{O}_{4}$ reference $\left(\eta_{10}=390 \mathrm{mV}\right)$, and the same trend is observed for IFP-5 (Figure S20). The difference in the catalytic activity between IFPs and $\mathrm{Co}_{3} \mathrm{O}_{4}-\mathrm{X}$ is even more evident when TOF values are compared (Figure S20c), suggesting that the active species of the two families should be quite different in nature. In other experiments, the comparison was focused between IFP and IFP-bt, finding nearly identical activity (Figure S20). More interestingly, the ECSA of the materials treated with base and IFP-8 are very close (ca. 12 $\mathrm{cm}^{2}$ ), and it is much higher than that of IFP-5 (ca. $\left.2 \mathrm{~cm}^{2}\right)$, in agreement with the fact that the loss of crystallinity might induce higher exposure of the active sites. This suggests that the $\mathrm{pH}$-induced degradation of the MOF might be one of the factors that drives the formation of the active species. ${ }^{37}$

Encouraged by these results, PXRD, ATR, and EXAFS experiments were performed ex situ before and after the catalysis, by plating the materials onto FTO as the electrode material (IFP@FTO).

The electrochemical studies of IFPs@FTO were carried out analogously to the characterization in NF. Initial LSVs confirm the reactivity order found in NF (Figure S21a,b). At the same time, during the $5 \mathrm{~h} \mathrm{CP}$ experiments performed at $5 \mathrm{~mA} / \mathrm{cm}^{2}$, the reduction of the potential and the increased number of exposed active sites (as indicated by the integrated charge of Co redox features and by ECSA, Table S5) indicate that the catalysts undergo an activation process, although with different rate with respect to that observed in NF. Nevertheless, the main kinetic descriptors for the intrinsic activity, that is, TOF and ECSA-normalized current density, decrease. In particular, TOF values (at $\eta=300 \mathrm{mV}$ ) were observed to almost half from $0.29 \mathrm{~s}^{-1}$ to $0.16 \mathrm{~s}^{-1}$ for IFP-8 and reduce from $0.35 \mathrm{~s}^{-1}$ to $0.25 \mathrm{~s}^{-1}$ for IFP-5. The decrease of the TOF value might be symptomatic for the loss of molecular behavior in favor of an aggregation process, which would likely be stronger in the case of IFP-8 than for IFP- 5 because of the higher drop of the TOF.

In order to better describe the activation process, after the 5 $\mathrm{h} C \mathrm{CP}$, the samples were investigated spectroscopically. The PXRD pattern and the ATR spectrum of IFP-5@FTO presented important attenuation of the signals (Figure 5). In particular, in the diffraction pattern, only the main peak at $10^{\circ}$ is visible, whereas in the infrared spectrum, all the features from the framework (1000-1700 $\left.\mathrm{cm}^{-1}\right)$ appear, but with reduced intensity. In the TEM images, it is apparent that the surface remains intact with minor degradation and roughness, suggesting that the initial Co distribution could be maintained or undergoes minor aggregation (Figure S22). These indications, together with minor metal leaching detected by ICP-OES measures (accounting for only 5\% of the total metal deposited), point toward the retention of the original structure of IFP-5.

A different scenario can be depicted for IFP-8@FTO because the attenuation of the PXRD pattern, the disappearance of ATR signals in the organic region, and the metal leaching of ca. $35 \%$ clearly indicate that the framework undergoes major degradation. Moreover, TEM images reveal the formation of amorphous and very small particles $(3-10$ $\mathrm{nm}$ ) embedded in a thin and plain surface (Figure $5 c, d$ and Figure S23).

However, all the samples clearly show a new dominant phase in the $400-650 \mathrm{~cm}^{-1}$ region of the ATR, corresponding to Co-O stretching (Figure 5)..$^{38,62-65}$ Such a broad band was proposed to be a convolution of $\mathrm{LCoO}\left(\mathrm{Co}^{4+}\right), \mathrm{LCoOH}$ $\left(\mathrm{Co}^{3+}\right)$, and $\mathrm{LCoOOH}\left(\mathrm{Co}^{3+}\right)$ species. ${ }^{44,66,67}$ In order to probe the chemical nature of the new phase, XAS measurements were performed. The spectrum of IFP-8 after catalysis exhibits a rising edge comparable to that of $\mathrm{Co}_{3} \mathrm{O}_{4}$ but with a clear shift to higher energy, having a pre-edge at $7710.4 \mathrm{eV}$ and a rising edge at $7725.6 \mathrm{eV}$. Such a shift, together with the structure of the XANES and the Fourier transformed EXAFS spectrum are compatible with the previously reported $\mathrm{Co}-\mathrm{Pi}$ or $\mathrm{CoO}$ $(\mathrm{OH}){ }^{68-70}$ Indeed, in the FT data, two dominant peaks can be observed, corresponding to $(\mathrm{Co}-\mathrm{O}$ at $1.90 \AA)$ and $\mathrm{Co}-\mathrm{Co}$ scattering paths with distance of $2.85 \AA$ (Figure $5 \mathrm{e}, \mathrm{f}$ ). Those signals, which are symptomatic of an octahedral environment, correspond to a single first shell of $6 \mathrm{~N} / \mathrm{O}$ scattering atoms, whereas the number of scattering atoms $(\mathrm{N})$ for the latter shell averages to $4.3 \pm 0.4$, which is lower than the 6 expected for $\mathrm{CoO}(\mathrm{OH})$. Subsequently, in analogy with the previously reported EXAFS analysis by Nocera et al., the model requires the inclusion of four more contributions: $\mathrm{Co}-\mathrm{O}(3.43 \AA)$, Co-Co $(4.94 \AA)$, multiple scattering $\mathrm{Co}-\mathrm{Co}-\mathrm{Co}(5.77 \AA)$, as intralayer paths and, finally, also the interlayer scattering shell Co-O $(3.72 \AA)$. Among them, the features at $\mathrm{R}(\AA)$ at 4.94 and $5.77 \AA$ are still in agreement with the $\mathrm{CoO}(\mathrm{OH})$ and bulk Co-Pi spectra and definitely rule out the presence of $\mathrm{Co}_{3} \mathrm{O}_{4}$ that does not have the path at $4.94 \AA$. However, it is important to notice that the coordination numbers for the paths at 4.94 
and 5.77 are 4.3 and 8.6, instead of 6 and 12, respectively. Such a loss indicates that the forming $\mathrm{Co}(\mathrm{O}) \mathrm{OH}$ exhibits significant lattice imperfections, in agreement with the traces of degradation observed in the TEM.

The kinetic of the degradation of the framework and the formation of $\mathrm{CoOOH}$ species was further studied by collecting ATR spectra at different times during the CP experiment (Figure 6).

Figure 6 suggests a correlation between the increment of the catalytic activity during time (the $\eta_{5}$ lowers), the formation of active species ( $\mathrm{Co}-\mathrm{O}$ bond signal), and the framework degradation (Figure S24). Moreover, full evolution/activation of IFP-8 occurs in only $3 \mathrm{~h}$; however, for IFP-5, the $\eta_{5}$ stabilizes after $5 \mathrm{~h}$, although the organic framework is still largely present. Furthermore, the ATR signal for the Co-O stretching of IFP-5 is 3 times lower in intensity than for IFP-8 (Figure S25).

A plausible explanation for different activation rates relies on the robustness of the organic linker, which should be imparted by the $-\mathrm{R}$ group for two main aspects. The first is that the - Me moiety from IFP-5 infers hydrophobic character to the MOF pores, repelling water and preventing the structural degradation. ${ }^{71}$ As a second reason, the degradation might depend on the different rate in the hydrolysis of the $-\mathrm{R}$ group in the $\mathrm{C} 2$ position of the imidazolium moiety, which is expected to be easier for the -OMe group than for the $-\mathrm{Me}$ one. ${ }^{46}$ An indirect proof for this was already found for the basic treated samples (Figure S7, vide supra). Once the hydrolysis occurs, the successive oxidative imidazolium ring-opening mechanism might be the most favored event under those conditions even at room temperature, as well described by Elabd et al. ${ }^{46,72}$

In this sense, the $-\mathrm{R}$ group modulates the extent of conversion of the MOF into the active species. For IFP-8, the fast and complete degradation of the framework leads to a higher amount of the active species, and discrete particles became visible in TEM. During electrochemical tests, IFP-8 exhibited higher capacitance over IFP-5, indicating that the same active species forms more active sites (Figure S25c) with respect to its $-\mathrm{Me}$ analogue.

\section{CONCLUSIONS}

IFP materials are demonstrated to be competent electrocatalysts toward OER with quantitative Faradaic yield, and in particular, IFP-8 exhibits performances that exceed those of the majority of other Co-based MOFs, especially for its durability. The ex situ characterization indicates that the catalytic activity can be correlated with the formation of the active phase, suggesting that a key feature to achieve high performances consists in controlling the rate of the hydrolysis of the framework, which drives the conversion of the MOF into catalytically active $\mathrm{Co}(\mathrm{O}) \mathrm{OH}$ phase. Such a control can be achieved by combining the design of suitable ligands with labile groups that are able to optimize the growth, size, and electric connection of catalytic efficient $\mathrm{Co}(\mathrm{O}) \mathrm{OH}$ nanoparticles. We envision that the in-depth analysis reported would help to bridge the gap between the single-site molecular well-structured materials and aggregated systems, guiding the improvement of catalytic materials under highly demanding conditions such as the OER.

\section{ASSOCIATED CONTENT}

\section{Supporting Information}

The Supporting Information is available free of charge at https://pubs.acs.org/doi/10.1021/acsaem.9b01977.

Linear sweep voltammetry of IFP-8 supported on nickel foam $5 \mathrm{mV} / \mathrm{s}$ up to $500 \mathrm{mV}$ overpotential (MP4)

Physical methods; synthetic procedures; electrochemical details and calculations, including the Faradaic efficiencies; further characterization by PXRD, SEM, and EXAFS; linear sweep voltammetry experiments; calculation of the Tafel Slope; long-term stability tests; ex situ ATR experiments; and tables summarizing the results of the fits for EIS, ECSA, and EXAFS (PDF)

\section{AUTHOR INFORMATION}

\section{Corresponding Author}

*E-mail: jlloret@iciq.es.

ORCID

Vlad Martin-Diaconescu: 0000-0002-7575-2237

Julio Lloret-Fillol: 0000-0002-4240-9512

\section{Notes}

The authors declare no competing financial interest.

\section{ACKNOWLEDGMENTS}

We thank the ICIQ Foundation, the European Research Foundation for project H2020-ERC-2015-CoG (J.L.-F.), H2020-FETPROACT-01-2016 A-LEAF (J.L.-F./A.B.), MINECO (CTQ2016-80038-R; J.L-F. and CTQ2017-86936-P; A.S.) and AGAUR 2017-SGR-1647 (J.L.-F.). S.S.M. thanks COFUND for postdoctoral scholarship. We would like to thank the support of the SAMBA beamline at the SOLEIL synchrotron (France) for their support and time for data acquisition. We thank to Prof. H.-J Holdt (University of Potsdam) for ligand precursor supplying.

\section{REFERENCES}

(1) Shaner, M. R.; Atwater, H. A.; Lewis, N. S.; McFarland, E. W. A comparative technoeconomic analysis of renewable hydrogen production using solar energy. Energy Environ. Sci. 2016, 9, 23542371.

(2) Jiao, Y.; Zheng, Y.; Jaroniec, M.; Qiao, S. Z. Design of electrocatalysts for oxygen- and hydrogen-involving energy conversion reactions. Chem. Soc. Rev. 2015, 44, 2060-2086.

(3) Seh, Z. W.; Kibsgaard, J.; Dickens, C. F.; Chorkendorff, I.; Nørskov, J. K.; Jaramillo, T. F. Combining theory and experiment in electrocatalysis: Insights into materials design. Science 2017, 355, eaad4998.

(4) Chen, D.; Chen, C.; Baiyee, Z. M.; Shao, Z.; Ciucci, F. Nonstoichiometric Oxides as Low-Cost and Highly-Efficient Oxygen Reduction/Evolution Catalysts for Low-Temperature Electrochemical Devices. Chem. Rev. 2015, 115, 9869-9921.

(5) Yin, Q.; Tan, J. M.; Besson, C.; Geletii, Y. V.; Musaev, D. G.; Kuznetsov, A. E.; Luo, Z.; Hardcastle, K. I.; Hill, C. L. A Fast Soluble Carbon-Free Molecular Water Oxidation Catalyst Based on Abundant Metals. Science 2010, 328, 342.

(6) Kanan, M. W.; Nocera, D. G. In Situ Formation of an OxygenEvolving Catalyst in Neutral Water Containing Phosphate and Co2+. Science 2008, 321, 1072.

(7) Zhu, Y. P.; Ma, T. Y.; Jaroniec, M.; Qiao, S. Z. Self-Templating Synthesis of Hollow Co3O4Microtube Arrays for Highly Efficient Water Electrolysis. Angew. Chem., Int. Ed. 2017, 56, 1324-1328.

(8) Meng, C.; Ling, T.; Ma, T.-Y.; Wang, H.; Hu, Z.; Zhou, Y.; Mao, J.; Du, X.-W.; Jaroniec, M.; Qiao, S.-Z. Atomically and Electronically 
Coupled Pt and CoO Hybrid Nanocatalysts for Enhanced Electrocatalytic Performance. Adv. Mater. 2017, 29, 1604607.

(9) Hu, H.; Guan, B.; Xia, B.; Lou, X. W. Designed Formation of Co3O4/NiCo2O4 Double-Shelled Nanocages with Enhanced Pseudocapacitive and Electrocatalytic Properties. J. Am. Chem. Soc. 2015, 137, 5590-5595.

(10) Jin, H.; Wang, J.; Su, D.; Wei, Z.; Pang, Z.; Wang, Y. In situ Cobalt-Cobalt Oxide/N-Doped Carbon Hybrids As Superior Bifunctional Electrocatalysts for Hydrogen and Oxygen Evolution. J. Am. Chem. Soc. 2015, 137, 2688-2694.

(11) Sheehan, S. W.; Thomsen, J. M.; Hintermair, U.; Crabtree, R. H.; Brudvig, G. W.; Schmuttenmaer, C. A. A molecular catalyst for water oxidation that binds to metal oxide surfaces. Nat. Commun. 2015, 6, 6469.

(12) Mills, A. Heterogeneous redox catalysts for oxygen and chlorine evolution. Chem. Soc. Rev. 1989, 18, 285-316.

(13) Roy, C.; Sebok, B.; Scott, S. B.; Fiordaliso, E. M.; Sørensen, J. E.; Bodin, A.; Trimarco, D. B.; Damsgaard, C. D.; Vesborg, P. C. K.; Hansen, O.; Stephens, I. E. L.; Kibsgaard, J.; Chorkendorff, I. Impact of nanoparticle size and lattice oxygen on water oxidation on NiFeOxHy. Nat. Catal. 2018, 1, 820-829.

(14) Li, J.-R.; Kuppler, R. J.; Zhou, H.-C. Selective gas adsorption and separation in metal-organic frameworks. Chem. Soc. Rev. 2009, 38, 1477-1504

(15) Mason, J. A.; Oktawiec, J.; Taylor, M. K.; Hudson, M. R.; Rodriguez, J.; Bachman, J. E.; Gonzalez, M. I.; Cervellino, A.; Guagliardi, A.; Brown, C. M.; Llewellyn, P. L.; Masciocchi, N.; Long, J. R. Methane storage in flexible metal-organic frameworks with intrinsic thermal management. Nature 2015, 527, 357.

(16) Tan, K.; Zuluaga, S.; Fuentes, E.; Mattson, E. C.; Veyan, J.-F.; Wang, H.; Li, J.; Thonhauser, T.; Chabal, Y. J. Trapping gases in metal-organic frameworks with a selective surface molecular barrier layer. Nat. Commun. 2016, 7, 13871.

(17) Huang, Y.-B.; Liang, J.; Wang, X.-S.; Cao, R. Multifunctional metal-organic framework catalysts: synergistic catalysis and tandem reactions. Chem. Soc. Rev. 2017, 46, 126-157.

(18) Zhu, L.; Liu, X.-Q.; Jiang, H.-L.; Sun, L.-B. Metal-Organic Frameworks for Heterogeneous Basic Catalysis. Chem. Rev. 2017, 117, $8129-8176$.

(19) Dhakshinamoorthy, A.; Li, Z.; Garcia, H. Catalysis and photocatalysis by metal organic frameworks. Chem. Soc. Rev. 2018, 47, 8134-8172.

(20) Furukawa, H.; Cordova, K. E.; O'Keeffe, M.; Yaghi, O. M. The Chemistry and Applications of Metal-Organic Frameworks. Science 2013, 341, 1230444.

(21) Liang, Z.; Qu, C.; Xia, D.; Zou, R.; Xu, Q. Atomically Dispersed Metal Sites in MOF-Based Materials for Electrocatalytic and Photocatalytic Energy Conversion. Angew. Chem., Int. Ed. 2018, 57, 9604-9633.

(22) Xu, Q.; Li, H.; Yue, F.; Chi, L.; Wang, J. Nanoscale cobalt metal-organic framework as a catalyst for visible light-driven and electrocatalytic water oxidation. New J. Chem. 2016, 40, 3032-3035.

(23) Shen, J.-Q.; Liao, P.-Q.; Zhou, D.-D.; He, C.-T.; Wu, J.-X.; Zhang, W.-X.; Zhang, J.-P.; Chen, X.-M. Modular and Stepwise Synthesis of a Hybrid Metal-Organic Framework for Efficient Electrocatalytic Oxygen Evolution. J. Am. Chem. Soc. 2017, 139, $1778-1781$.

(24) Duan, J.; Chen, S.; Zhao, C. Ultrathin metal-organic framework array for efficient electrocatalytic water splitting. Nat. Commun. 2017, 8,15341 .

(25) Lu, X.-F.; Liao, P.-Q.; Wang, J.-W.; Wu, J.-X.; Chen, X.-W.; He, C.-T.; Zhang, J.-P.; Li, G.-R.; Chen, X.-M. An Alkaline-Stable, Metal Hydroxide Mimicking Metal-Organic Framework for Efficient Electrocatalytic Oxygen Evolution. J. Am. Chem. Soc. 2016, 138, $8336-8339$.

(26) Gao, J.; Cong, J.; Wu, Y.; Sun, L.; Yao, J.; Chen, B. Bimetallic Hofmann-Type Metal-Organic Framework Nanoparticles for Efficient Electrocatalysis of Oxygen Evolution Reaction. ACS Appl. Energy Mater. 2018, 1, 5140-5144.
(27) Wang, X.-L.; Dong, L.-Z.; Qiao, M.; Tang, Y.-J.; Liu, J.; Li, Y.; Li, S.-L.; Su, J.-X.; Lan, Y.-Q. Exploring the Performance Improvement of the Oxygen Evolution Reaction in a Stable Bimetal-Organic Framework System. Angew. Chem., Int. Ed. 2018, 57, 9660-9664.

(28) Li, F.-L.; Shao, Q.; Huang, X.; Lang, J.-P. Nanoscale Trimetallic Metal-Organic Frameworks Enable Efficient Oxygen Evolution Electrocatalysis. Angew. Chem., Int. Ed. 2018, 57, 1888-1892.

(29) Meng, Q.; Yang, J.; Ma, S.; Zhai, M.; Lu, J. A Porous Cobalt (II) Metal-Organic Framework with Highly Efficient Electrocatalytic Activity for the Oxygen Evolution Reaction. Polymers 2017, 9, 676.

(30) Xu, Y.; Li, B.; Zheng, S.; Wu, P.; Zhan, J.; Xue, H.; Xu, Q.; Pang, $H$. Ultrathin two-dimensional cobalt-organic framework nanosheets for high-performance electrocatalytic oxygen evolution. J. Mater. Chem. A 2018, 6, 22070-22076.

(31) Zhang, X.; Sun, W.; Du, H.; Kong, R.-M.; Qu, F. A Co-MOF nanosheet array as a high-performance electrocatalyst for the oxygen evolution reaction in alkaline electrolytes. Inorg. Chem. Front. 2018, 5, 344-347.

(32) Ding, D.; Shen, K.; Chen, X.; Chen, H.; Chen, J.; Fan, T.; Wu, R.; Li, Y. Multi-Level Architecture Optimization of MOF-Templated Co-Based Nanoparticles Embedded in Hollow N-Doped Carbon Polyhedra for Efficient OER and ORR. ACS Catal. 2018, 8, 78797888.

(33) Abdelkader-Fernández, V. K.; Fernandes, D. M.; Balula, S. S.; Cunha-Silva, L.; Pérez-Mendoza, M. J.; López-Garzón, F. J.; Pereira, M. F.; Freire, C. Noble-Metal-Free MOF-74-Derived Nanocarbons: Insights on Metal Composition and Doping Effects on the Electrocatalytic Activity Toward Oxygen Reactions. ACS Appl. Energy Mater. 2019, 2, 1854-1867.

(34) Ma, T. Y.; Dai, S.; Jaroniec, M.; Qiao, S. Z. Metal-Organic Framework Derived Hybrid Co3O4-Carbon Porous Nanowire Arrays as Reversible Oxygen Evolution Electrodes. J. Am. Chem. Soc. 2014, 136, 13925-13931.

(35) Aijaz, A.; Masa, J.; Rösler, C.; Xia, W.; Weide, P.; Botz, A. J. R.; Fischer, R. A.; Schuhmann, W.; Muhler, M. Co@Co3O4 Encapsulated in Carbon Nanotube-Grafted Nitrogen-Doped Carbon Polyhedra as an Advanced Bifunctional Oxygen Electrode. Angew. Chem., Int. Ed. 2016, 55, 4087-4091.

(36) Huang, Z.-F.; Song, J.; Du, Y.; Xi, S.; Dou, S.; Nsanzimana, J. M. V.; Wang, C.; Xu, Z. J.; Wang, X. Chemical and structural origin of lattice oxygen oxidation in $\mathrm{Co}-\mathrm{Zn}$ oxyhydroxide oxygen evolution electrocatalysts. Nat. Energy 2019, 4, 329-338.

(37) Huang, J.; Li, Y.; Huang, R.-K.; He, C.-T.; Gong, L.; Hu, Q.; Wang, L.; Xu, Y.-T.; Tian, X.-Y.; Liu, S.-Y.; Ye, Z.-M.; Wang, F.; Zhou, D.-D.; Zhang, W.-X.; Zhang, J.-P. Electrochemical Exfoliation of Pillared-Layer Metal-Organic Framework to Boost the Oxygen Evolution Reaction. Angew. Chem., Int. Ed. 2018, 57, 4632-4636.

(38) Jiang, J.; Huang, L.; Liu, X.; Ai, L. Bioinspired Cobalt-Citrate Metal-Organic Framework as an Efficient Electrocatalyst for Water Oxidation. ACS Appl. Mater. Interfaces 2017, 9, 7193-7201.

(39) Cao, J.; Lei, C.; Yang, J.; Cheng, X.; Li, Z.; Yang, B.; Zhang, X.; Lei, L.; Hou, Y.; Ostrikov, K. An ultrathin cobalt-based zeolitic imidazolate framework nanosheet array with a strong synergistic effect towards the efficient oxygen evolution reaction. J. Mater. Chem. A 2018, 6, 18877-18883.

(40) Cao, J.; Wang, K.; Chen, J.; Lei, C.; Yang, B.; Li, Z.; Lei, L.; Hou, Y.; Ostrikov, K. Nitrogen-Doped Carbon-Encased Bimetallic Selenide for High-Performance Water Electrolysis. Nano-Micro Lett. 2019, 11, 67.

(41) Liu, S.; Wang, Z.; Zhou, S.; Yu, F.; Yu, M.; Chiang, C.-Y.; Zhou, W.; Zhao, J.; Qiu, J. Metal-Organic-Framework-Derived Hybrid Carbon Nanocages as a Bifunctional Electrocatalyst for Oxygen Reduction and Evolution. Adv. Mater. 2017, 29, 1700874.

(42) Zhou, J.; Dou, Y.; Zhou, A.; Guo, R.-M.; Zhao, M.-J.; Li, J.-R. MOF Template-Directed Fabrication of Hierarchically Structured Electrocatalysts for Efficient Oxygen Evolution Reaction. Adv. Energy Mater. 2017, 7, 1602643.

(43) Wei, G.; Zhou, Z.; Zhao, X.; Zhang, W.; An, C. Ultrathin Metal-Organic Framework Nanosheet-Derived Ultrathin Co3O4 
Nanomeshes with Robust Oxygen-Evolving Performance and Asymmetric Supercapacitors. ACS Appl. Mater. Interfaces 2018, 10, 23721-23730.

(44) Jayaramulu, K.; Masa, J.; Morales, D. M.; Tomanec, O.; Ranc, V.; Petr, M.; Wilde, P.; Chen, Y.-T.; Zboril, R.; Schuhmann, W.; Fischer, R. A. Ultrathin 2D Cobalt Zeolite-Imidazole Framework Nanosheets for Electrocatalytic Oxygen Evolution. Adv. Sci. 2018, 5, 1801029.

(45) Mondal, S. S.; Bhunia, A.; Demeshko, S.; Kelling, A.; Schilde, U.; Janiak, C.; Holdt, H.-J. Synthesis of a Co(ii)-imidazolate framework from an anionic linker precursor: gas-sorption and magnetic properties. CrystEngComm 2014, 16, 39-42.

(46) Mondal, S. S.; Bhunia, A.; Kelling, A.; Schilde, U.; Janiak, C.; Holdt, H.-J. A supramolecular $\mathrm{Co}(\mathrm{ii}) 14$-metal-organic cube in a hydrogen-bonded network and a $\mathrm{Co}(\mathrm{ii})$-organic framework with a flexible methoxy substituent. Chem. Commun. 2014, 50, 5441-5443.

(47) Li, X.; Niu, Z.; Jiang, J.; Ai, L. Cobalt nanoparticles embedded in porous $\mathrm{N}$-rich carbon as an efficient bifunctional electrocatalyst for water splitting. J. Mater. Chem. A 2016, 4, 3204-3209.

(48) Coates, J. Interpretation of infrared spectra, a practical approach. In Encyclopedia of Analytical Chemistry: Applications, Theory, and Instrumentation; Meyers, R. A., Ed.; John Wiley \& Sons, Inc.: Hoboken, NJ, 2006.

(49) Trotochaud, L.; Ranney, J. K.; Williams, K. N.; Boettcher, S. W. Solution-Cast Metal Oxide Thin Film Electrocatalysts for Oxygen Evolution. J. Am. Chem. Soc. 2012, 134, 17253-17261.

(50) Chakthranont, P.; Kibsgaard, J.; Gallo, A.; Park, J.; Mitani, M.; Sokaras, D.; Kroll, T.; Sinclair, R.; Mogensen, M. B.; Jaramillo, T. F. Effects of Gold Substrates on the Intrinsic and Extrinsic Activity of High-Loading Nickel-Based Oxyhydroxide Oxygen Evolution Catalysts. ACS Catal. 2017, 7, 5399-5409.

(51) Han, Y.; Zhai, J.; Zhang, L.; Dong, S. Direct carbonization of cobalt-doped NH2-MIL-53(Fe) for electrocatalysis of oxygen evolution reaction. Nanoscale 2016, 8, 1033-1039.

(52) Seo, B.; Sa, Y. J.; Woo, J.; Kwon, K.; Park, J.; Shin, T. J.; Jeong, H. Y.; Joo, S. H. Size-Dependent Activity Trends Combined with in Situ X-ray Absorption Spectroscopy Reveal Insights into Cobalt Oxide/Carbon Nanotube-Catalyzed Bifunctional Oxygen Electrocatalysis. ACS Catal. 2016, 6, 4347-4355.

(53) Masa, J.; Xia, W.; Sinev, I.; Zhao, A.; Sun, Z.; Grützke, S.; Weide, P.; Muhler, M.; Schuhmann, W. MnxOy/NC and CoxOy/NC Nanoparticles Embedded in a Nitrogen-Doped Carbon Matrix for High-Performance Bifunctional Oxygen Electrodes. Angew. Chem., Int. Ed. 2014, 53, 8508-8512.

(54) Li, L.; Tian, T.; Jiang, J.; Ai, L. Hierarchically porous Co3O4 architectures with honeycomb-like structures for efficient oxygen generation from electrochemical water splitting. J. Power Sources 2015, 294, 103-111.

(55) Zou, X.; Huang, X.; Goswami, A.; Silva, R.; Sathe, B. R.; Mikmeková, E.; Asefa, T. Cobalt-Embedded Nitrogen-Rich Carbon Nanotubes Efficiently Catalyze Hydrogen Evolution Reaction at All pH Values. Angew. Chem. 2014, 126, 4461-4465.

(56) Yang, Y.; Fei, H.; Ruan, G.; Tour, J. M. Porous Cobalt-Based Thin Film as a Bifunctional Catalyst for Hydrogen Generation and Oxygen Generation. Adv. Mater. 2015, 27, 3175-3180.

(57) Hou, Y.; Lohe, M. R.; Zhang, J.; Liu, S.; Zhuang, X.; Feng, X. Vertically oriented cobalt selenide/NiFe layered-double-hydroxide nanosheets supported on exfoliated graphene foil: an efficient 3D electrode for overall water splitting. Energy Environ. Sci. 2016, 9, 478483.

(58) Feng, L.-L.; Yu, G.; Wu, Y.; Li, G.-D.; Li, H.; Sun, Y.; Asefa, T.; Chen, W.; Zou, X. High-Index Faceted Ni3S2 Nanosheet Arrays as Highly Active and Ultrastable Electrocatalysts for Water Splitting. J. Am. Chem. Soc. 2015, 137, 14023-14026.

(59) Sa, Y. J.; Park, S. O.; Jung, G. Y.; Shin, T. J.; Jeong, H. Y.; Kwak, S. K.; Joo, S. H. Heterogeneous Co-N/C Electrocatalysts with Controlled Cobalt Site Densities for the Hydrogen Evolution Reaction: Structure-Activity Correlations and Kinetic Insights. ACS Catal. 2019, 9, 83-97.
(60) Pei, Z.; Tang, Z.; Liu, Z.; Huang, Y.; Wang, Y.; Li, H.; Xue, Q.; Zhu, M.; Tang, D.; Zhi, C. Construction of a hierarchical 3D Co/Ncarbon electrocatalyst for efficient oxygen reduction and overall water splitting. J. Mater. Chem. A 2018, 6, 489-497.

(61) Hao, Y.; Xu, Y.; Liu, W.; Sun, X. Co/CoP embedded in a hairy nitrogen-doped carbon polyhedron as an advanced tri-functional electrocatalyst. Mater. Horiz. 2018, 5, 108-115.

(62) Jiang, J.; Zhang, A.; Li, L.; Ai, L. Nickel-cobalt layered double hydroxide nanosheets as high-performance electrocatalyst for oxygen evolution reaction. J. Power Sources 2015, 278, 445-451.

(63) Stern, L.-A.; Hu, X. Enhanced oxygen evolution activity by $\mathrm{NiOx}$ and $\mathrm{Ni}(\mathrm{OH}) 2$ nanoparticles. Faraday Discuss. 2014, 176, $363-$ 379

(64) Nurlaela, E.; Ould-Chikh, S.; Llorens, I.; Hazemann, J.-L.; Takanabe, K. Establishing Efficient Cobalt-Based Catalytic Sites for Oxygen Evolution on a Ta3N5 Photocatalyst. Chem. Mater. 2015, 27, 5685-5694.

(65) Xing, C.; Liu, Y.; Su, Y.; Chen, Y.; Hao, S.; Wu, X.; Wang, X.; Cao, H.; Li, B. Structural Evolution of Co-Based Metal Organic Frameworks in Pyrolysis for Synthesis of Core-Shells on Nanosheets: Co@CoOx@Carbon-rGO Composites for Enhanced Hydrogen Generation Activity. ACS Appl. Mater. Interfaces 2016, 8, 1543015438.

(66) Moon, G.-h.; Yu, M.; Chan, C. K.; Tüysüz, H. Highly Active Cobalt-Based Electrocatalysts with Facile Incorporation of Dopants for the Oxygen Evolution Reaction. Angew. Chem., Int. Ed. 2019, 58, 3491-3495.

(67) Yeo, B. S.; Bell, A. T. Enhanced Activity of Gold-Supported Cobalt Oxide for the Electrochemical Evolution of Oxygen. J. Am. Chem. Soc. 2011, 133, 5587-5593.

(68) Risch, M.; Khare, V.; Zaharieva, I.; Gerencser, L.; Chernev, P.; Dau, H. Cobalt-Oxo Core of a Water-Oxidizing Catalyst Film. J. Am. Chem. Soc. 2009, 131, 6936-6937.

(69) Van Oversteeg, C. H. M.; Doan, H. Q.; De Groot, F. M. F.; Cuk, T. In situ X-ray absorption spectroscopy of transition metal based water oxidation catalysts. Chem. Soc. Rev. 2017, 46, 102-125.

(70) Bergmann, A.; Jones, T. E.; Martinez Moreno, E.; Teschner, D.; Chernev, P.; Gliech, M.; Reier, T.; Dau, H.; Strasser, P. Unified structural motifs of the catalytically active state of Co(oxyhydr)oxides during the electrochemical oxygen evolution reaction. Nat. Catal. 2018, 1, 711-719.

(71) Park, K. S.; Ni, Z.; Côté, A. P.; Choi, J. Y.; Huang, R.; UribeRomo, F. J.; Chae, H. K.; O’Keeffe, M.; Yaghi, O. M. Exceptional chemical and thermal stability of zeolitic imidazolate frameworks. Proc. Natl. Acad. Sci. U. S. A. 2006, 103, 10186.

(72) Ye, Y.; Elabd, Y. A. Relative Chemical Stability of ImidazoliumBased Alkaline Anion Exchange Polymerized Ionic Liquids. Macromolecules 2011, 44, 8494-8503. 